\title{
The Concept of Hybrid Reactor of Tokamak and Molten-salt Thorium Blanket for Producing ${ }^{233} \mathrm{U}$ out of Neutron Field
}

\author{
Alekseev P. N., Azizov E. A., Dokuka V. N., Gladush G. G., Hajrutdinov R. R., Subbotin S. A., \\ Shimkevich A. L."
}

National Research Centre Kurchatov Institute, Russia

Copyright $(\mathcal{C} 2015$ by authors, all rights reserved. Authors agree that this article remains permanently open access under the terms of the Creative Commons Attribution License 4.0 International License

\begin{abstract}
A concept is offered for tokamak and molten-salt thorium blanket with liquid-metal mass-exchanger which allows an uninterrupted extraction of protactinium from the blanket and its accumulation in a cascade salt trap separately from fission products. At uninterrupted extraction of protactinium from neutron field with the same rate, such a facility can become attractive for industrial production of nuclear fuel $\left({ }^{233} \mathrm{U}\right)$ from thorium. For this, it is offered to use a reduction extraction of radio-nuclides into a liquid-metal carrier (directly contacting with the molten salt) by managing RedOx potential (Fermi level) of the salt composition. Establishing Fermi level in the first cascade of molten-salt trap only for oxidizing the lanthanides allows extracting only them from the liquid-metal carrier. In the second cascade of this trap, one can extract protactinium by shifting down Fermi level at higher oxidation potential. For correct operation of the trap cascades, the lanthanides portion in the second cascade will be less than $0.01 \%$ of the first one and the portion of protactinium in the first cascade will be four orders less than in the second one.
\end{abstract}

Keywords Neutron Source, Molten-salt Blanket, Radio Nuclides, RedOx Management, Liquid-metal Exchanger, Molten-salt Trap

\section{Introduction}

The hybrid of tokamak (as a thermonuclear source of neutrons), molten-salt thorium blanket, and liquid-metal mass-exchanger can become effective for producing ${ }^{233} \mathrm{U}$ from thorium as a nuclear fuel for thermal reactors. In this system, one can exclude uncontrollable reactor runaway and feasible radiation of the environment at coolant loss due to continuous and uninterrupted removing radio-nuclides from a reactor core. Such a small-sized facility can operate as a hybrid fusion-fission reactor for fueling the PWR.

At the same time, a specificity of this problem put-by imposes enhanced requirements to the important unit of the facility as a molten-salt blanket (MSB) containing thorium. Plasma aspects of a thermonuclear source of neutrons (TSN) are short considered as opposed to questions for online decontamination of MSB and ways for extracting useful products from the salt composition.

In this paper, it is offered to use the combined scheme of current leading the plasma in tokamak. At induction lead-in of the current, a diverter plasma configuration is formed and then, the plasma current increases to demanded value by means of neutral injection. Numerical calculations have shown that one can obtain a neutron flux of $\sim 15 \mathrm{MW}$ and its power density in the blanket surface of $\sim 0.2 \mathrm{MW} / \mathrm{m}^{2}$ at the injection of double-weight hydrogen by power of $23 \mathrm{MW}$. It can provide a rate of protactinium production in the salt composition of $0.7 \mathrm{FLiNaK}-0.3 \mathrm{ThF}_{4}$ up to $\sim 4 \cdot 10^{-7} \mathrm{~mol} / \mathrm{s}$.

\section{Possible Scenarios for Combined Leading a Plasma Current in TSN}

A merely induction input of plasma into tokamak imposes exacting requirements to inductor windings and to a power supply. For weakening these requirements, it is expedient to organize induction-non-induction current lead which can be divided into two stages. At the first, an increase of a current is provided at the induction stage for forming diverter configurations, then at the second, the neutral injection rises and an entrainment current is generated together with heating plasma. Such the combined lead in current of plasma allows to halve a supply of poloidal power in the inductor windings and to reduce its initial current.

Two variants of calculation of plasma parameters are carried out (see Table 1) for the following levels of neutral 
injection power, $P_{\mathrm{ni}}[\mathrm{MW}]: 27$ (1) and 30 (2).

Table 1. Plasma parameters for two levels of neutral injection power, $P_{\mathrm{ni}}$

\begin{tabular}{|c|c|c|}
\hline \multirow{2}{*}{ Plasma parameters } & \multicolumn{2}{|c|}{ Variant } \\
\hline & 1 & 2 \\
\hline Average density of tritium, $n_{\mathrm{T}}, 10^{19} \mathrm{~m}^{-3}$ & 5.59 & 5.59 \\
\hline Average density of deuterium, $n_{\mathrm{D}}, 10^{19} \mathrm{~m}^{-3}$ & 1.40 & 1.40 \\
\hline Injecting beams power, $\mathrm{MW}$ & $15 / 12$ & $15 / 15$ \\
\hline Absorbed power of neutral injection, $\Delta P_{\mathrm{ni}}$, MW & 21.60 & 24.00 \\
\hline Power absorbed in plasma, $\Delta P_{\mathrm{p}}, \mathrm{MW}$ & 24.09 & 26.49 \\
\hline Plasma current, $I_{\mathrm{p}}$, MA & 3.68 & 3.90 \\
\hline Non-induction current, $I_{\mathrm{n}}$, MA & 4.13 & 4.60 \\
\hline Drive current, $I_{\mathrm{d}}, \mathrm{MA}$ & 2.74 & 3.15 \\
\hline Bootstrap current, $I_{\mathrm{b}}$, MA & 1.39 & 1.44 \\
\hline Ohmic current, $I_{\mathrm{O}}$, MA & -0.45 & -0.69 \\
\hline Entrainment current of neutral injection, $I_{\mathrm{n}}$, MA & 2.37 & 2.74 \\
\hline Power time, $\tau_{\mathrm{E}}, \mathrm{s}$ & 0.35 & 0.35 \\
\hline Average temperature of electrons, $\left\langle T_{\mathrm{e}}\right\rangle, \mathrm{keV}$ & 4.99 & 5.40 \\
\hline Average temperature of ions, $\left\langle T_{\mathrm{i}}\right\rangle, \mathrm{keV}$ & 4.99 & 5.58 \\
\hline $\begin{array}{l}\text { Temperature of electrons in the center of plasma, } \\
\qquad T_{\mathrm{C}}(0), \mathrm{keV}\end{array}$ & 10.15 & 11.07 \\
\hline $\begin{array}{l}\text { Temperature of ions in the center of plasma, } T_{\mathrm{i}}(0) \text {, } \\
\mathrm{keV}\end{array}$ & 11.20 & 12.80 \\
\hline Power of neutrons, $P_{\mathrm{n}}, \mathrm{MW}$ & 14.92 & 17.96 \\
\hline Stability supply in the center of plasma, $q(0)$ & 1.94 & 1.55 \\
\hline Internal inductance of cord, $\mathrm{l}_{\mathrm{i}}(3)$ & 0.48 & 0.47 \\
\hline Normalized beta, $\beta_{\mathrm{N}}$ & 3.39 & 3.61 \\
\hline
\end{tabular}

A dynamics of full neutron power, $P_{\mathrm{n}}$, at developing discharge is shown in Fig.1.

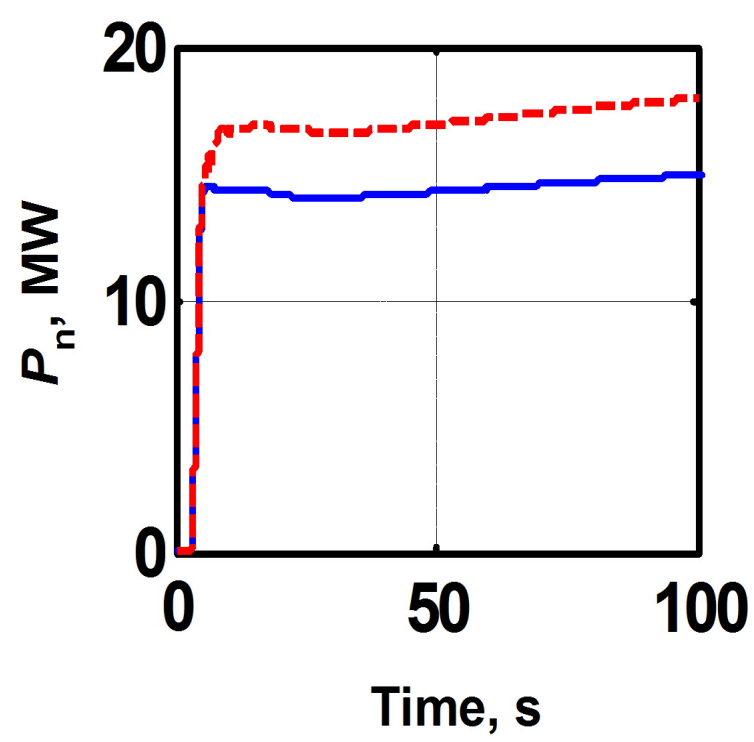

Figure 1. Output dynamics of full neutron power, $P_{\mathrm{n}}$, for the first variant (blue line) and the second one (red)

It is visible that the power of neutron generation increases on $2.5 \mathrm{MW}$ in growing power of beam injected in plasma. Here, the appreciable contribution $(\sim 2 \mathrm{MW})$ is brought by
D-T reaction at decelerating deuterons in plasma. Numerical calculations have shown that the power of neutron flux of neutrons may be obtained up to $\sim 15 \mathrm{MW}$ at deuterons injection of $23 \mathrm{MW}$ and the density of this flux on blanket surface will be $\sim 0.2 \mathrm{MW} / \mathrm{m}^{2}$.

\section{The Concept of Thermonuclear Fuel Production}

For producing ${ }^{233} \mathrm{U}$, it is possible to use a fuel composition, FLiNaK- $\mathrm{ThF}_{4}$, in the molten-salt blanket. In nuclear TSN reactions of the isotope, ${ }^{232} \mathrm{Th}$, each fast neutron of $\sim 14 \mathrm{MeV}$ generates $\sim 1.7$ nuclei of protactinium, ${ }^{233} \mathrm{~Pa}$, that can be continuously extracted online from the blanket by a liquid-metal carrier into a molten-salt trap. ${ }^{233} \mathrm{U}$ isotope will be accumulated there out of neutron field by $\beta$-delay of protactinium. As $\mathrm{FLiNaK}-\mathrm{ThF}_{4}$ contains lithium, it is transformed under neutron irradiation to tritium which can partially provide TSN by thermonuclear fuel.

Calculations by means of program MCNP-4C [1], files library ENDF/B-VI of estimated nuclear data and program NJOY99 [2] for preparing the nuclear data of MSB have shown that it is possible in principle organizing fuel production including tritium by means of TSN and molten-salt blanket [3].

At the same time, it is necessary a precise monitoring and change of reduction-oxidation (RedOx) potential of molten salt in order to effectively remove radio-nuclides from MSB. Such the unit can be made from the solid electrolyte, $\mathrm{Na}^{+}-\beta "-\mathrm{Al}_{2} \mathrm{O}_{3}$, as an ionic-exchange membrane with unipolar sodium conductivity $[4,5]$.

\section{A Concept for Online Cleaning the MSB}

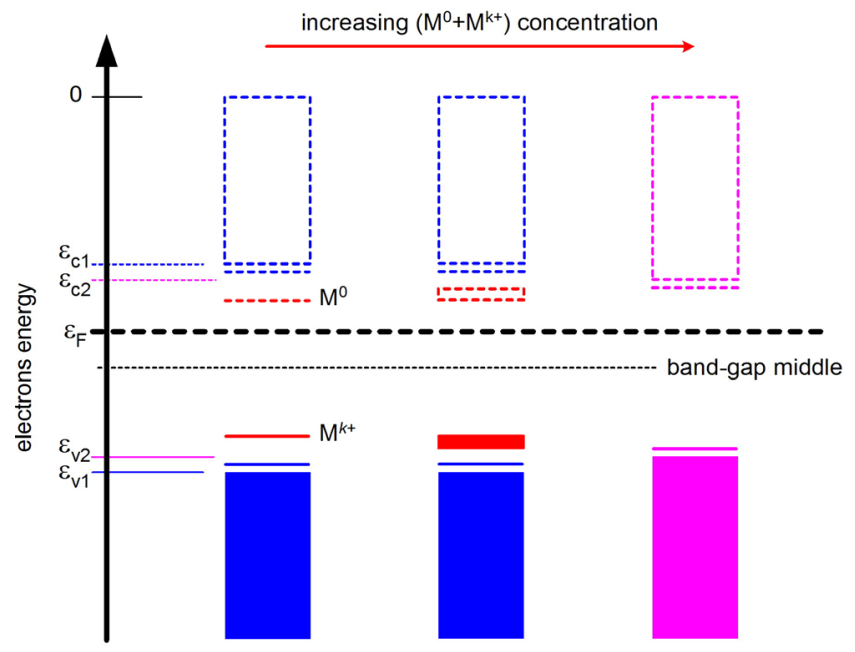

(a)

(b)

(c)

Figure 2. The band structure of molten salt for three concentrations of dissolved impurity, $\mathrm{M}=\mathrm{M}^{0}+\mathrm{M}^{k+}$ : a) $c_{\mathrm{M}}<0.1 \% \mathrm{~mol}$, б) $1<c_{\mathrm{M}}<3 \% \mathrm{~mol}$, в) $c_{\mathrm{M}}>10 \% \mathrm{~mol}$; the full lines and boxes denote impurity levels and valence bands occupied by electrons; dotted lines and boxes - vacant impurity levels and conduction bands; $\varepsilon_{\mathrm{F}}$ is Fermi level 
A selective extraction of metal radio-nuclides from liquid salts is possible only when their concentrations are low as seen in Fig. 2 where the increase of impurity concentrations, $c_{\mathrm{M}}$, shows the mixture of their bands in the electronic structure of molten salt [3].

One can see that any metal impurity at the low concentration in the molten salt has the allowed local levels in the band gap (a) that are transformed in an impurity band (b), and then, are integrated into conduction or valence bands (c) at increasing its concentration. Then, the bottom of conduction band shifts down $\left(\varepsilon_{\mathrm{c} 1} \rightarrow \varepsilon_{\mathrm{c} 2}\right)$, the top of valence band shifts up $\left(\varepsilon_{\mathrm{v} 1} \rightarrow \varepsilon_{\mathrm{v} 2}\right)$, and the width of the band gap $\varepsilon_{\mathrm{g}}=$ $\left(\varepsilon_{\mathrm{c}}-\varepsilon_{\mathrm{v}}\right)$ is decreased [3].

This electrochemical window is suitable for extracting metallic radio-nuclides from the molten salt only at low concentrations. Hence, it is necessary to remove continuously radio nuclides from molten-salt blanket in order to hold their concentration at a low level. For this, they should install a "molten-salt/liquid-metal" mass-exchanger in a MSB bypass line in order to extract reductively metal impurities from salt to a liquid-metal carrier (LMC) as shown in Fig.3. This carrier, for its turn, gives these impurities back to a molten salt cascade trap schematically shown in Fig.4 [3].

At the full extraction of metal radio-nuclides by mass-exchanger from the flowing salt, its volumetric rate, $v_{\mathrm{s}}$, through the mass-exchanger will be a limiting factor for cleaning the MSB. Really, the change of radio-nuclide concentration in the molten-salt blanket with its specific source, $j_{i}$, is defined by kinetic equation [3]

$$
\frac{d c_{i}}{d t}=-\left(v_{\mathrm{s}} / V_{\mathrm{s}}\right) c_{i}+j_{i},
$$

where $V_{\mathrm{s}}$ is the salt volume in blanket. We obtain the solution

$$
c_{i}=\left[1-\exp \left(-t / t_{\mathrm{o}}\right)\right] t_{\mathrm{o}} j_{i},
$$

which gives an asymptotic value of the impurity concentration in MSB:

$$
c_{i s}=t_{\mathrm{o}} j_{i} .
$$

It is necessary to notice that $t_{\mathrm{o}}=V_{\mathrm{s}} / v_{\mathrm{s}}$ is an inverse value of MSB circulating factor of the mass-exchanger bypass line. Obviously, the salt flow rate through the mass-exchanger is more ( $t_{\mathrm{o}}$ is less), the residual radio-nuclides concentration in MSB is lower.

Protactinium production rate will be $\sim 4 \cdot 10^{-7} \mathrm{~mol} / \mathrm{s}$ at specific density $0.2 \mathrm{MW} / \mathrm{m}^{2}$ of neutrons power on the MSB wall. Then, we can obtain from Eq. (3) the balanced protactinium concentration of $c_{i s} \sim 0.1 \mathrm{ppm}$ in the molten salt, $0.7 \mathrm{FLiNaK}-0.3 \mathrm{ThF}_{4}$, (having density of $3.3 \mathrm{~g} / \mathrm{cm}^{3}$ and molecular weight of 121.3 [1]) if the molten-salt flow rate through the mass-exchanger is equal to $5001 /$ hour. Taking into account the production rate of protactinium, it is possible to show that MSB without cleaning radio-nuclides will reach this concentration by 20 minutes. Therefore, continuous removing the products of nuclear reactions for the MSB is actual.

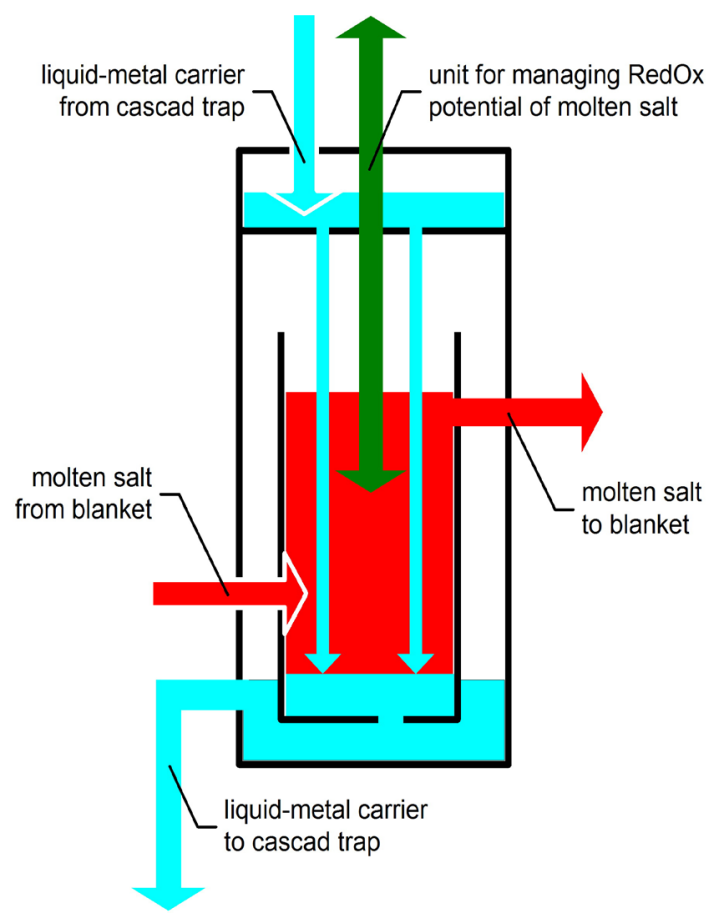

Figure 3. The schematic diagram of salt/metal mass-exchanger

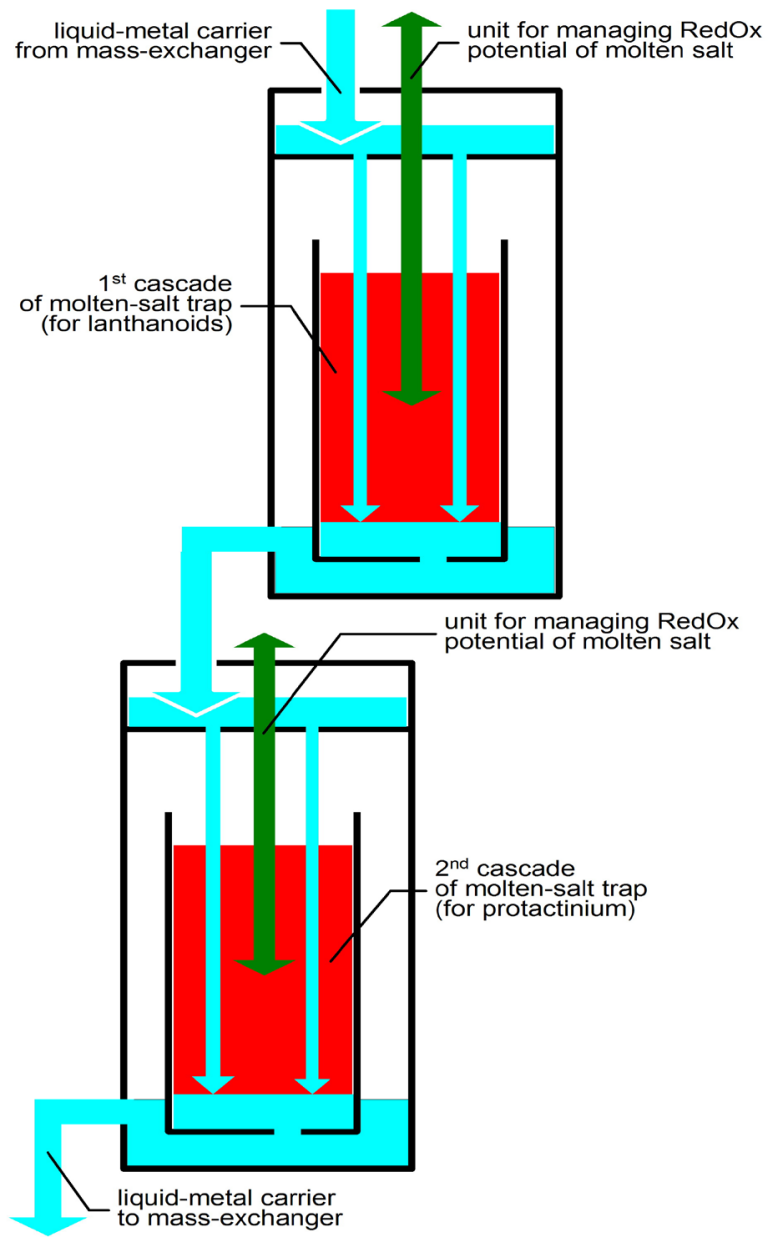

Figure 4. The schematic diagram of molten-salt cascade trap for radio-nuclides 


\section{An Estimate of Protactinium and Lanthanides Separation in the Cascade Trap}

The first cascade of molten-salt trap (MST) for lanthanides (see Fig.4) does not differ physically from the second one for protactinium storing. They differ functionally by establishing different Fermi levels of the molten salt in cascades $\varepsilon_{\mathrm{Pa}}<\varepsilon_{\mathrm{F} 1}<\varepsilon_{\mathrm{Ln}}$ and $\varepsilon_{\mathrm{F} 2}<\varepsilon_{\mathrm{Pa}}<\varepsilon_{\mathrm{Ln}}$. These levels are lower than $\varepsilon_{\mathrm{Fex}}$ in the salt of mass-exchanger (see Fig.3): $\varepsilon_{\mathrm{Pa}}$ $<\varepsilon_{\mathrm{Ln}}<\varepsilon_{\mathrm{Fex}}$, that provides in MST cascades selective oxidative extraction of radio-nuclides from LMC. Here, $\varepsilon_{\mathrm{Pa}}$ is electronic level of protactinium in the band gap of molten salt and $\varepsilon_{\mathrm{Ln}}$ is the lower electronic level of lanthanides.

The band structure in the first MST cascade (for lanthanides) in contact with LMC is shown in Fig.5. This structure of the second cascade (for protactinium) is shown in Fig.6 as well as the one for mass-exchanger shown in Fig.7.

The stationary concentrations of protactinium ions $\left[\mathrm{Pa}^{+3}\right]_{0}$ and atoms $\left[\mathrm{Pa}^{0}\right]_{0}$ into MSB as well as the ones of lanthanides $\left(\left[\mathrm{Ln}^{+3}\right]_{0},\left[\mathrm{Ln}^{0}\right]_{0}\right)$ will be established at the constant source of radio-nuclides and the flow-rate of molten salt through the mass-exchanger.

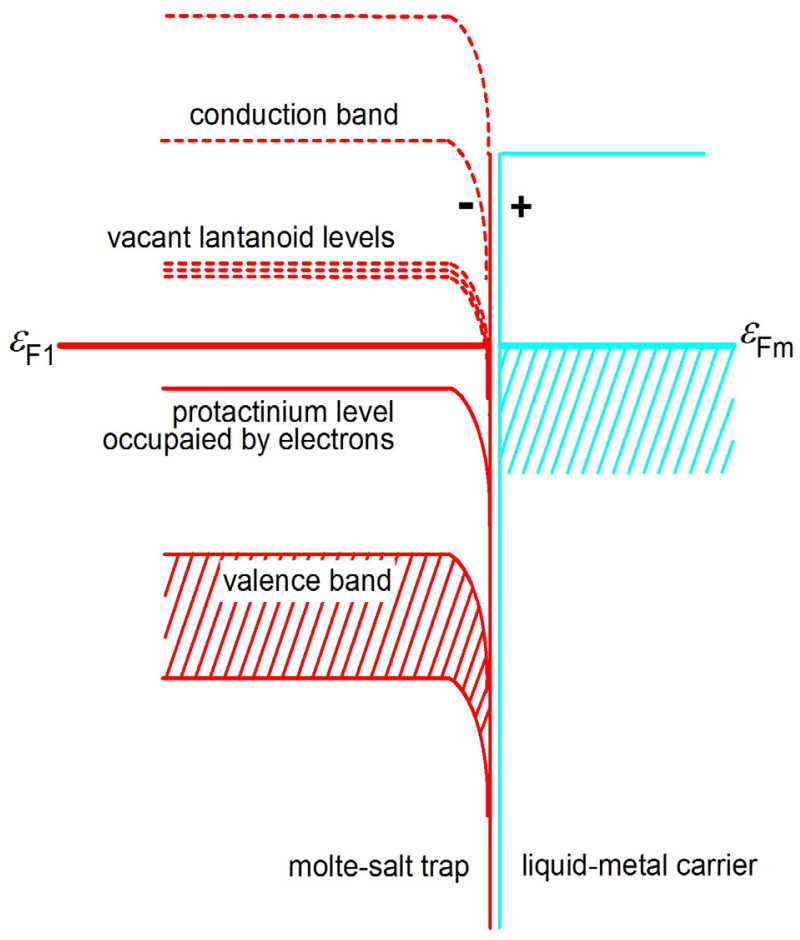

Figure 5. The band salt structure of the first MST cascade (for lanthanides) in contact with LMC

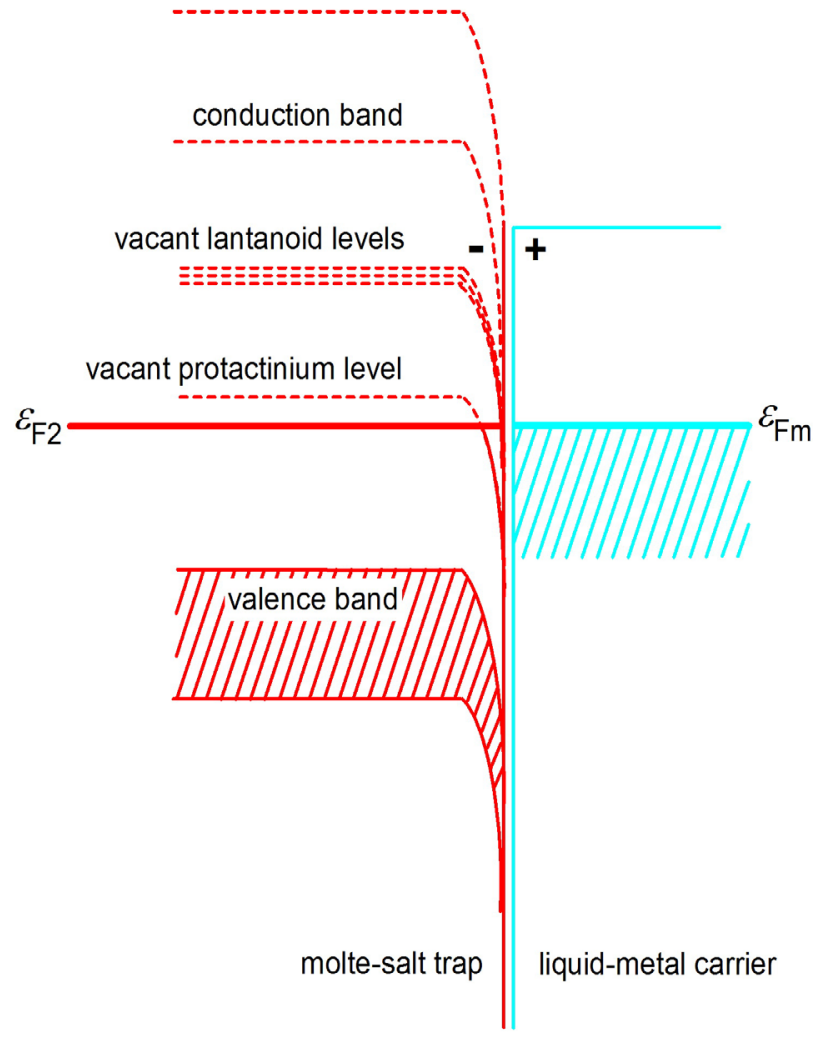

Figure 6. The band salt structure of the second MST cascade (for protactinium) in contact with LMC

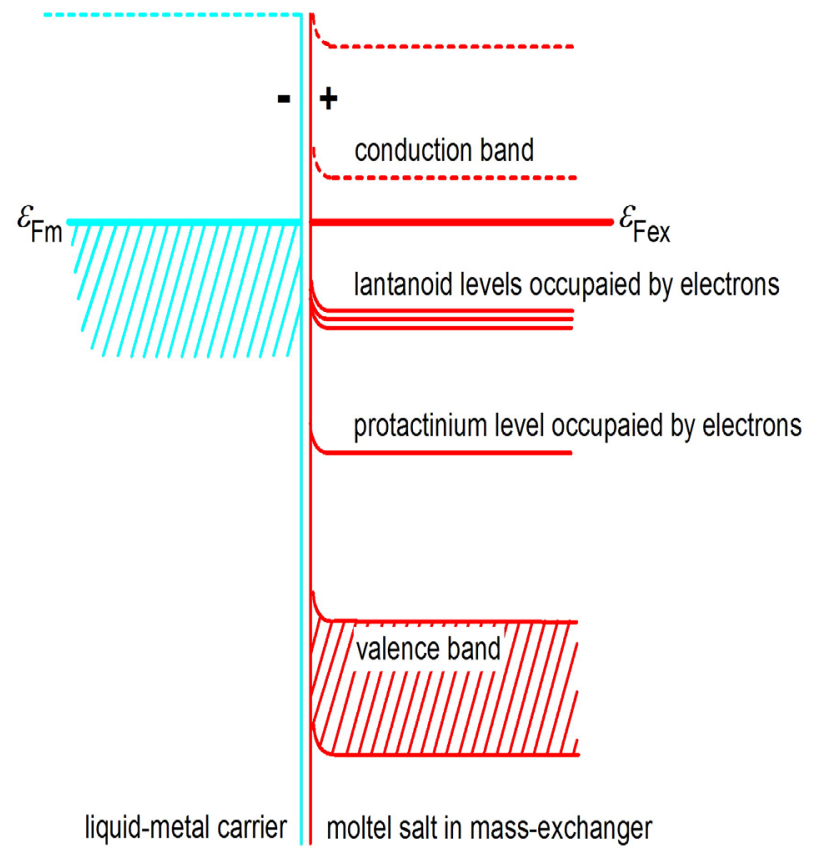

Figure 7. The band salt structure of the mass-exchanger in contact with LMC 
At the same time, the concentrations of these impurities in MST cascades will change due to a specially organized mode of the continuous and separate collection of them in ionic form $\left(\mathrm{Ln}^{+3}, \mathrm{~Pa}^{+3}\right)$ when an electron population of levels for protactinium, $\varepsilon_{\mathrm{Pa}}$, and lanthanides, $\varepsilon_{\mathrm{Ln}}$, in each block of the exchange system (mass-exchanger and two cascades of MST) is defined by the equations

$$
\begin{gathered}
{\left[\mathrm{Pa}^{0}\right]_{0} /\left[\mathrm{Pa}^{+3}\right]_{0}=\exp \left[3\left(\varepsilon_{\mathrm{Fex}}-\varepsilon_{\mathrm{Pa}}\right) / k_{\mathrm{B}} T\right]=\alpha_{\mathrm{ex}}>1,} \\
{\left[\mathrm{Ln}^{0}\right]_{0} /\left[\mathrm{Ln}^{+3}\right]_{0}=\exp \left[3\left(\varepsilon_{\mathrm{Fex}}-\varepsilon_{\mathrm{Ln}}\right) / k_{\mathrm{B}} T\right]=\beta_{\mathrm{ex}}>1,} \\
{\left[\mathrm{~Pa}^{0}\right]_{1} /\left[\mathrm{Pa}^{+3}\right]_{1}=\exp \left[3\left(\varepsilon_{\mathrm{F} 1}-\varepsilon_{\mathrm{Pa}}\right) / k_{\mathrm{B}} T\right]=\alpha_{1}>1,} \\
{\left[\mathrm{Ln}^{0}\right]_{1} /\left[\mathrm{Ln}^{+3}\right]_{1}=\exp \left[3\left(\varepsilon_{\mathrm{F} 1}-\varepsilon_{\mathrm{Ln}}\right) / k_{\mathrm{B}} T\right]=\beta_{1} \quad<1,} \\
{\left[\mathrm{~Pa}^{0}\right]_{2} /\left[\mathrm{Pa}^{+3}\right]_{2}=\exp \left[3\left(\varepsilon_{\mathrm{F} 2}-\varepsilon_{\mathrm{Pa}}\right) / k_{\mathrm{B}} T\right]=\alpha_{2} \quad<1,} \\
{\left[\mathrm{Ln}^{0}\right]_{2} /\left[\mathrm{Ln}^{+3}\right]_{2}=\exp \left[3\left(\varepsilon_{\mathrm{F} 2}-\varepsilon_{\mathrm{Ln}}\right) / k_{\mathrm{B}} T\right]=\beta_{2} \quad<<1 .}
\end{gathered}
$$

Here $k_{\mathrm{B}}$ is Boltzmann constant equal to $8.62 \cdot 10^{-5} \mathrm{eV} / \mathrm{K}$ and $T$ is Kelvin temperature.

The concentrations $\left[\mathrm{Pa}^{0}\right]_{0},\left[\mathrm{Ln}^{0}\right]_{0}$ in the stationary mode of MSB are the input data for the first cascade of MST and $\left[\mathrm{Pa}^{0}\right]_{1},\left[\mathrm{Ln}^{0}\right]_{1}$ are the ones for the second cascade of MST when the exchange system reaches balance on the outlet of cascades. The initial cationic concentrations, $\left[\mathrm{Pa}^{+3}\right]_{1,2}$ and $\left[\mathrm{Ln}^{+3}\right]_{1,2}$, of radio-nuclides in MST are equal to zero.

Obviously, it is necessary that

$$
\begin{aligned}
& {\left[\mathrm{Pa}^{+3}\right]_{1}(t)<<\left[\mathrm{Pa}^{+3}\right]_{2}(t),} \\
& {\left[\mathrm{Ln}^{+3}\right]_{1}(t) \gg>\left[\mathrm{Ln}^{+3}\right]_{2}(t),}
\end{aligned}
$$

for effective separating radio-nuclides in MST at each instant of time, $t$.

For guaranteeing these conditions, we have to find corresponding kinetic characteristics of the exchange system from the equation

$$
\frac{d}{d t}\left[\operatorname{Ln}^{+3}\right]_{1}=K\left\{\left[\operatorname{Ln}^{0}\right]_{0}-\left[\operatorname{Ln}^{0}\right]_{1}(t)\right\},
$$

which has the simple solution

$$
\Delta\left[\operatorname{Ln}^{+3}\right]_{1}=\left(\left[\operatorname{Ln}^{0}\right]_{0} / \beta_{1}\right)\left(1-e^{-\beta_{1} \tau}\right)
$$

taking into account (2) and $\tau \equiv K \Delta t$.

For estimating these concentrations, it is necessary to know electronic levels $\varepsilon_{\mathrm{Pa}}$ and $\varepsilon_{\mathrm{Ln}}$ in the band gap of the molten salt. Such data is no for the time present. From the general reasons, it is possible assuming that the difference, $\varepsilon_{\mathrm{Ln}}-\varepsilon_{\mathrm{Pa}}$, does not exceed $0.4 \mathrm{eV}$. Then, we will obtain from (5) and (6): $\alpha_{1}=94, \alpha_{2} \sim 10^{-6}, \beta_{1} \sim 10^{-6}$, and $\beta_{2} \sim 10^{-14}$, establishing Fermi levels, $\varepsilon_{\mathrm{F} 1}$ and $\varepsilon_{\mathrm{F} 2}$, from the condition: $\varepsilon_{\mathrm{Ln}}$ $-\varepsilon_{\mathrm{F} 1}=\varepsilon_{\mathrm{Pa}}-\varepsilon_{\mathrm{F} 2}=0.3 \mathrm{eV}$ and $T=773 \mathrm{~K}\left(k_{\mathrm{B}} T \sim 0.066 \mathrm{eV}\right)$.

Then, we is simplifies (9) to equality, $\Delta\left[\mathrm{Ln}^{+3}\right]_{1}=\left[\mathrm{Ln}^{0}\right]_{0}$, at $\tau=1$. On the analogy of (9), we find that $\Delta\left[\operatorname{Ln}^{+3}\right]_{2}=\left[\operatorname{Ln}^{0}\right]_{1}$ and accordingly $\Delta\left[\mathrm{Ln}^{+3}\right]_{2} / \Delta\left[\mathrm{Ln}^{+3}\right]_{1}=\beta_{1} \sim 10^{-6}$ taking into account Eq.5, i.e. the second part of condition (7) is correct.
In substituting $\left[\mathrm{Pa}^{+3}\right]$ and $\left[\mathrm{Pa}^{0}\right]$ in (8) instead of $\left[\mathrm{Ln}^{+3}\right]$ and $\left[\operatorname{Ln}^{0}\right]$, we will obtain

$$
\Delta\left[\mathrm{Pa}^{+3}\right]_{1}=\left(\left[\mathrm{Pa}^{0}\right]_{0} / \alpha_{1}\right)\left(1-e^{-\alpha_{1} \tau}\right) \sim\left[\operatorname{Ln}^{0}\right]_{0} / \alpha_{1}
$$

by the analogy of (9). Further, we obtain $\left[\mathrm{Pa}^{0}\right]_{1}=\left[\mathrm{Pa}^{0}\right]_{0}$ and $\Delta\left[\mathrm{Pa}^{+3}\right]_{2}=\left[\mathrm{Pa}^{0}\right]_{1}$ from (5) and (6), that is $\Delta\left[\mathrm{Pa}^{+3}\right]_{2} / \Delta\left[\mathrm{Pa}^{+3}\right]_{1}=$ 94 as an evidence for correcting the first part of condition (7).

If establishing Fermi level, $\varepsilon_{\mathrm{F} 1}$, in the first cascade of MST in the middle between $\varepsilon_{\mathrm{Pa}}$ and $\varepsilon_{\mathrm{Ln}}$ we will obtain equal proportions:

$$
\Delta\left[\mathrm{Pa}^{+3}\right]_{1} / \Delta\left[\mathrm{Pa}^{+3}\right]_{2} \sim \Delta\left[\mathrm{Ln}^{+3}\right]_{2} / \Delta\left[\mathrm{Ln}^{+3}\right]_{1} \sim 10^{-4},
$$

that is the protactinium portion in the first cascade will amount to $0.01 \%$ of the second one, and the lanthanides in the second cascade will be in $10^{4}$ times less than in the first one.

\section{Conclusions}

Numerical calculations have shown that the power of neutron flux of neutrons may be obtained up to $\sim 15 \mathrm{MW}$ at deuterons injection of $23 \mathrm{MW}$ and the density of this flux on blanket surface will be $\sim 0.2 \mathrm{MW} / \mathrm{m}^{2}$ that can provide producing protactinium in the salt composition of $0.7 \mathrm{FLiNaK}-0.3 \mathrm{ThF}_{4}$ up to $4 \mathrm{~kg} / \mathrm{m}^{2}$ a year.

In the frame of molten-salt band model, the concept is developed for reductive extracting protactinium and lanthanides from the molten-salt blanket by the liquid-metal carrier and subsequent oxidative extracting and separate storing them in the different cascades of molten-salt trap.

\section{REFERENCES}

[1] J. F. Briesmeister, Ed., "MCNP - A General Monte Carlo N-Particle Transport Code, Version 4C," LA-13709-M (April 2000).

[2] M.S. Sohal et al, Engineering Database of Liquid Salt Thermophysical and Thermochemical Properties / The report of Idaho National Laboratory, INL/EXT-10-18297 March 2010 .

[3] Consept of Green Nuclear Power Engineering/ E.P. Velikhov, E.A. Azizov, P.N. Alekseev, M.I. Gurevich, S.A. Subbotin, A.L. Shimkevich// Voprosy Atomnoi Nauki I Tekhnki. Seriya: Thermonuclear synthesis, 2013, v.36, issue1, p. 5-16.

[4] P.N. Alekseev, E.I. Grishanin, and A.L Shimkevich, RF Patent 115,954 (2012).

[5] P.N. Alekseev and A.L. Shimkevich, On Fine Management of Fuel Composition in Molten Salt Reactors // International Journal of Nuclear Energy Science and Engineering, V. 2 (2012), P. 88. 